\title{
Addressing Student Motivation, Self-regulation, and Engagement in Flipped Classroom to Decrease Boredom
}

\author{
Alessandra La Marca and Leonarda Longo
}

\begin{abstract}
The interplay teacher regulation and student self-regulation of learning is an important topic in contemporary theories of teaching and learning. The pervasiveness of the boredom experienced by many students, along with its deleterious effects, clearly implies that educators, and teachers responsible for the design of academic settings should pay more attention to this emotion. With regard to the prevention or reduction of boredom, the present findings suggest that specific measures could focus on increasing the perceived values of activities in achievement settings. This study used mixed methodologies, including a student perception inventory and observations, to investigate whether teachers differ in their regulation mode during flipped lesson. This paper is an attempt to examine the impact of flipped classroom model on student's learning with particular focus on teacher's reflections on their learning process. The contribution of this research is that it qualifies the instructional practices to shift from content acquisition act to knowledge expression and creation act. In addition, the paper would give a contribution to people looking for pedagogical applications of virtual and blended learning environments for developing multiple ways to express what learners know and be able to do.
\end{abstract}

Index Terms-Boredom, flipped, observations of teacher practices, self-regulation.

\section{INTRODUCTION}

Several motivation theories may be relevant to a discussion of boredom in learning environments: these include attribution theory, self-regulated learning, and goals theory.

Researches on self-regulated learning show that self-regulation is an important factor in student learning.

Recent studies have gone beyond the effect of boredom on achievement. These studies indicate that boredom is relate to: students' stress, impulsivity, procrastination, and it has significant consequences leading to truancy and school dropout (etc.).

Since schools were first established, educators from the inside and reformers from the outside, have tried to change schools for the better. Question are frequently asked why

Manuscript received October 12, 2015; revised December 23, 2015. This work was supported in part by the Research Project of National Interest (PRIN, 2010/2011) "Success training, inclusion and social cohesion: innovative strategies, ICT and valuation models" (Scientific Coordinator of the National Research Programme is Professor Gaetano Domenici). Starting from the standard measurement of learning, achieved through an external evaluation integrated with the internal evaluation prepared by the teachers, the Research Unit of Palermo, coordinated by Professor Giuseppe Zanniello, aims at both improving individual performance of pupils and teachers' professional skills.

The authors are with the Educational Department, University of Palermo, $90100 \quad$ Italy (e-mail: alessandra.lamarca@ unipa.it, leonarda.longo@unipa.it). some students are successful in some schools while in others they are not. Why do some students do not complete schooling? Why do some students come to school regularly while others stop attending?

Even when students decide to study, simply knowing that there are alternatives can affect the students' self-regulation.

Emotional and cognitive engagement are related to the degree to which students value and connect with classroom activities, and whether or not they believe that these activities are relevant.

Boredom acts to withdraw attention from the task at hand [1]. It causes a student to work to distract herself and the result is paying attention to something other than what is going on in the classroom, or other than what the teacher may be presenting. Talking with a classmate may be more stimulating and carry a higher value. Boredom reduces academic motivation and attention. Lack of attention is thought to be one of a number of components of boredom. Self-awareness of attention, will experience boredom [2].

The teacher, as a component of the learning environment, can play an important role in decreasing boredom students and developing student self-regulated learning.

The objective of this paper is to develop an immersive learning model to assure the quality of learning through the flipped classroom.

The present study derives its significance from the fact that it is the first attempt, to the best of the researcher's knowledge, to develop an immersive learning model to learn from/with virtual and e-learning in all programs including e-courses. More specifically, the study is expected to urge specialists to question the traditional learning models and strategies in the light of the proposed model. Moreover, it helps staff members using flipped classroom to evaluate depth of meaning and the generation of retainable knowledge and cognition.

Flipped learning environments offer unique opportunities for student learning, as well as some unique challenges. By moving direct instruction from the class group space to the individual students' learning spaces, time and space are freed up for the class as a learning community to explore the most difficult concepts of the course. Likewise, because students are individually responsible for learning the basics of new material, they gain regular experience with employing self-regulated learning strategies they would not have in an flipped environment.

\section{STUdENT ENGAGEMENT}

\section{A. Student Engagement}

Engagement is multidimensional and involves emotions, 
behaviors, and cognitions [3]. Student engagement decreases as student transition from middle to high school. Positive emotions support engagement and coping in the school setting Emotions influence engagement which then impacts learning and achievement. Most important, emotions have strong effects on attention engagement with academic tasks. Engagement results in positive outcomes and decreases negative emotions. Conceptually, engagement and self-regulated learning overlap. Engagement predicts learning grades and behavior in the short-term [4].

\section{B. Non-cognitive Factors Influencing Student Achievement}

There are a number of non-cognitive factors which can affect achievement: emotion and emotion regulation, student goals and student engagement, socio-affective skill, learning process, dispositions, organizational skill, academic motivation, self-regulation, metacognitive skill, study habits, coping strategies, personality factors such as openness and emotional stability

To complicate matters further, the literature surrounding non-cognitive factors in school achievement encompasses research threads from several different areas, resulting in conflicting terms, theories, hypotheses, and conflicting research studies.

\section{Attention}

Inattention is thought to be one of a number of components of boredom. Most studies that examine the connection between boredom and attention are correlational studies [5].

Attention can be regarded as one of the main 'battlefields' of self-regulation, as stimulus-driven influences and goal-directed processing often compete for limited attention resources [6]. According to the elaborated intrusion theory of desire [7], for instance, tempting stimuli may automatically attract attention due to their motivational salience. To the degree that individuals fail to redirect attention away from the tempting stimulus, desire-related thoughts and emotions may receive additional elaboration in working memory and develop into 'elaborated desires' [7]. Elaborated desires use up WMC [8] and thus may crowd out of working memory other goal representations.

Self- awareness of attention may be particularly important.

Task that a student could finish without focused attention can be easily affected by distraction [5].

\section{REDUCING BOREDOM IN THE SCHOOL}

\section{A. Antecedents of State Boredom}

Students' perceptions that a given task or piece of work is meaningless; students' reaction to tasks in which there is insufficient direction; tasks for which resources are inadequate; restrictive situations (students cannot leave class); learning situations during which students have very little control; tasks that are disliked and students would rather be doing something else; teaching approaches that are not exciting or stimulating; teaching that does not match students' skill or ability levels; when goals are not clear or focused [9].

\section{B. The Experience of Boredom}

Although it's clear that boredom can be a serious problem, the scientific study of boredom remains an obscure field, and boredom itself is still poorly understood. Even though it's a common experience, boredom hasn't been clearly defined within the scientific community.

Early on, researchers conned being distracted to boredom in the classroom [10].

Teachers sense when students are bored in the classroom. Eyes glaze over, their minds drift off, and a pall descends upon the class.

Eastwood [5] and his colleagues hope to help in the discovery and development of new strategies that ease the problems of boredom sufferers and address the potential dangers of cognitive errors that are often associated with boredom.

Today's students are also finding it increasingly intolerable because virtually everything outside of the classroom is on speed dial and "teacher talk" seems to be in slow motion. It's also clear that engaging student minds is getting harder and that boredom is becoming an unfortunate and pervasive stressor that can have significant consequences for future health and well being.

\section{Students' Perceptions of Boredom in the Classroom}

Contributing to boredom is the perception by many students that school learning is meaningless, or not connected with their goals and interests and not valuable in their lives. Meaningless learning is initiated by others, requires little personal involvement by learners, affects (at best) a small part of learners' lives, and is viewed by learners as not relevant to their goals. Unfortunately much classroom teaching reinforces this perception, especially when teachers lecture and students passively listen.

Boredom is real. This point seems obvious, but as we will discuss later, the phrase, "I'm bored" can mean many different things. Yet sometimes, "I'm bored," means just that. For example, you wouldn't take the average 14-year-old student to a graduate school physics lecture. It's beyond their capacity to understand and, therefore, is irrelevant and boring for them. You'll get the same response if you take them to a second grade classroom. Listen to your students.

Explore faith and disciple them by doing a little homework and discovering what they are gifted in and passionate about. Use their boredom as guard rails to determine if you've gone over their heads or if you aren't challenging them enough. You'll probably find that some students get bored easily, while others have a longer attention span. It's impossible to cater to every student we serve, but adapting your presentation and activities to fit multiple personality types can encourage and challenge a wider range of students.

Macklem [11] argues that boredom shouldn't be ignored or dismissed as a passing phase. Examines various types of boredom as well as gender and cultural differences. Provides theory on causes of boredom in students. Details how student self-regulation, motivation, and engagement can be improved. Describes specific roles teachers can play in controlling boredom.

Learning cannot be made meaningful to students by simply telling them why the learning is important. 


\section{Interactive Teaching Strategies}

Rather, meaningful learning requires a reorganization of the teaching-learning process. Teachers become learning facilitators who provide resources for students to attain their goals or solve problems that are important to them. Rather than all students doing the same thing at the same time there will be much differentiation with some working in groups and others individually, some inside and others outside of the classroom, and so forth. Although such latitude may not be possible across an entire school day, allowing students some choices is predicted to increase their perception of learning as meaningful to them and thereby help to reduce boredom.

Guide students by suggesting open-ended, yet positive alternatives to wallowing in boredom.

Mora [12] noted that more interactive hands-on activities resulted in decreased boredom among students in the classroom. Students rate interactive approaches highly.

Students want more interactive classes and prefer activities that involve interaction with teachers and peers. Ways to keep students interested: Change up the outline of the class. Do fun activities so that students have something to look forward to in class.

Flipped learning changes the traditional roles of teacher and student. Flipped learning is student-centered.

The learner-centered label now gets attached to teaching strategies, teachers, classes, programs, departments and institutions. Like many trendy descriptors in higher education, with widespread use comes a certain definitional looseness. Flipped learning, student engagement and other strategies that involve students and mention learning are called learner-centered. And although learner-centered teaching and efforts to involve students have a kind of bread and butter relationship, they are not the same thing. In the interest of more definitional precision, I'd like to propose five characteristics of teaching that make it learner-centered.

1) Learner-centered teaching engages students in the hard, messy work of learning: we ask the questions, we call on students, we add detail to their answers. We offer the examples. We organize the content. We do the preview and the review. On any given day, in most classes teachers are working much harder than students.

2) Learner-centered teaching includes explicit skill instruction: learner-centered teachers teach students how to think, solve problems, evaluate evidence, analyze arguments, generate hypotheses - all those learning skills essential to mastering material in the discipline. A few students do, but they tend to be the students most like us and most students aren't that way. Research consistently confirms that learning skills develop faster if they are taught explicitly along with the content.

3) Learner-centered teaching encourages students to reflect on what they are learning and how they are learning it: learner-centered teachers talk about learning. In casual conversations, they ask students what they are learning. In class they may talk about their own learning. They challenge student assumptions about learning and encourage them to accept responsibility for decisions they make about learning; like how they study for exams, when they do assigned reading, whether they revise their writing or check their answers. Learner-centered teachers include assignment components in which students reflect, analyze and critique what they are learning and how they are learning it. The goal is to make students aware of themselves as learners and to make learning skills something students want to develop.

4) Learner-centered teaching motivates students by giving them some control over learning processes: teachers decide what students should learn, how they learn it, the pace at which they learn, the conditions under which they learn and then teachers determine whether students have learned. Students aren't in a position to decide what content should be included in the course or which textbook is best, but when teachers make all the decisions, the motivation to learn decreases and learners become dependent. Learner-centered teachers search out ethically responsible ways to share power with students. They might give students some choice about which assignments they complete. They might let students set assignment deadlines within a given time window. They might ask students to help create assessment criteria.

5) Learner-centered teaching encourages collaboration: it sees classrooms (online or face-to-face) as communities of learners. Learner-centered teachers recognize, and research consistently confirms, that students can learn from and with each other. Certainly the teacher has the expertise and an obligation to share it, but teachers can learn from students as well. Learner-centered teachers work to develop structures that promote shared commitments to learning. They see learning individually and collectively as the most important goal of any educational experience.

\section{FliPPED ClASSROOM Model Might DECREASE BOREDOM}

A learning space should be able to motivate learners and promote learning as an activity, support collaborative, provide a personalized and inclusive environment, and be flexible in the face of changing needs [13].

Several studies indicate that training using flipped classroom can lead to improved attention in students. Wasson in 1981 recommended that an effective strategy to deal with misbehavior at school might be to focus on the internal causes of boredom. Wasson proposed that boredom may be due to inattention.

Today the challenge for teachers is how to use students' interest and experience of technology in their learning process. Indeed technology has become a significant part of our life and work [14].

The flipped classroom [15] has had many recent popularity; it has been extended in many schools abroad and has made a good effect.

We have considered the literature on student-created digital videos [16], [17] and we believe that flipped classroom model through different technological devices and applications would make students more active in their learning, and would give students responsibility in the researching of the content. 
Flipped classrooms are shifting the way teachers provide instruction by inverting traditional teaching methods to engage students in the learning process. Using technology, lectures are moved out of the classroom and delivered online as a means to free up class time for interaction and collaboration. In order to effectively implement a flipped classroom, teachers must possess a set of requisites and technical skills, conceptual knowledge and pedagogical expertise.

Flipped classroom model is in contrast to the traditional model in which "first exposure" occurs via lecture in class, with students assimilating knowledge through homework. In a traditional classroom, students are first taught and then accompanied by a practical training session.

Usually teachers assign homework to their students to reinforce learning concepts.

In this way, students are left on the receiving end of a one-way communication process that do little to promote attention, motivation social interaction or encourage critical thought.

A learning community, either in-person or online, would help to provide guidance through initiation and expand on the shared experiences of the individuals.

By contrast, the flipped classroom model presents learning as an active, social process in which learners use existing knowledge and prior experiences to build an individual understanding of new material.

Only in a flipped classroom, the instructional design is to reverse or "flip" this traditional approach.

In traditional methods of classroom instruction, instructors uses class time mainly for lectures, and students are expected to complete assignments at home. However, a flipped classroom switches these roles; students watch pre-recorded lessons online at home and may complete assignments before engaging with the instructor in person. Class time is used to engage the students in interactive activities that reinforce and build upon concepts they viewed in the pre-recorded lessons.

In essence, "flipping the classroom" means that students gain first exposure to new material outside of class, usually via reading or lecture videos, and then use class time to do the harder work of assimilating that knowledge, perhaps through problem-solving, discussion, or debates [18].

In a flipped classroom, learning materials are made available to students for self-learning before class starts, while in-class time is used for the student-teacher interaction.

Approaches to teaching and learning are increasingly influenced by the introduction of new technologies and innovative use of time and space.

\section{TRAINING PROGRAM FliPPED CLASSROOM}

To encourage the experimentation of activities based on use of motivating technologies and on innovative methodology is possible to adopt the flipped classroom model One of the strengths of the flipped classroom is that it allows teachers and students to explore technologies in an environment unconstrained by the limits imposed by a traditional teaching time/space dimension.

Technologies can support teachers to deliver flexible opportunities that actively involve students through a flipped classroom model.

According to the flipped classroom model [15] video was assigned for homework and students was given time in class the next day to do activities. All students watched videos of teachers explaining the material that would be used in class the day after. This allowed teachers to answer specific questions about the lab and to assist students during activity, as well as discuss in class. Students were responsible for viewing the videos and asking appropriate questions.

The teacher was simply there to provide expert feedback. The students were responsible for completing and sharing their work. Because a solution guide was available, students were motivated to learn, not just to complete the assignments in a rote manner.

A training program was designed for helping to learn how to teach with the flipped classroom and remediate attention problems in the classroom. Six weeks of training using this approach can be helpful in improving attention and self-regulation. Although longer and more intensive training can have better results, an 6-week intervention could reasonably be implemented in schools.

An intensive training with 30 teachers was carried out including 6 weeks of specific training through flipped model. Several activities were designed, including active teaching, how to create video lectures, content selection for the flipped classroom, implementing flipped lectures, helping your students learn flipped, and assessing the flipped classroom.

All subjects demonstrated significant gains in attention following of flipped classroom training.

\section{OBSERVATIONS OF TEACHER PRACTICES IN FLIPPED ClASSROOM}

For the observational study, we selected 12 teachers. All teachers agreed to participate and completed an informed consent form. The teachers were videotaped during one complete lesson; the lessons ranged from 40 to $45 \mathrm{~min}$. The pedagogical practices of the 12 teachers were scored by two independent observers.

The observers employed an observation scheme incorporating five categories corresponding to the five subscales of the MSBS (Disengagement, High Arousal, Low Arousal, Inattention, and Time Perception) [19] and three categories of the student ALM inventory [20], [20]. In addition to scoring the teacher's pedagogical practices on every subscales at $10 \mathrm{~min}$ intervals, the observers provided an overall category score after they observed the entire lesson, keeping in mind the scored teacher practices throughout the lesson. Only the latter scores were used for this study.

Observers were trained in four stages. First of all, observers were given an overview of the system, an explanation of the codes, and procedures for using the observation codebook as a reference. Secondly, the trainer and the observers practiced coding and debriefing observations as a group using video clips. At a third stage, the observers practiced coding with the trainer in classrooms that were not in the study. Finally, reliability was established in project classrooms between the trainer and individual observers and maintained via periodic 
retesting. Observers that met and maintained an $80 \%$ or higher rate of agreement with the trainer were allowed to observe project classrooms.

The observers received instructions from the first about how to interpret the categories of the observation scheme. A videotaped lesson was used for instruction, but was not included in the observations. Furthermore, the observers were informed about the interpretation of the three categories of teachers based on students' perceptions. However, the observers were blind to the teacher category membership based on student perceptions.

Video has become a widely used tool in teacher education and teacher learning [22], most likely because observations can provide a detailed description of teacher behavior and may therefore be a good method for gaining insight into teacher classroom practices. It appeared that the teachers were categorized based on the classroom observations, in the same categories as in the student perceptions.

Analysis of the video with the help of the observation instrument showed that the between-observer reliability was almost perfect. The simple and clearly structured instrument may be used by teachers or in teachers' education.

\section{CONCLUSION}

The findings of the present research have a number of implications for practice. Whereas it may be speculated that boredom can have beneficial effects in some individuals under specific circumstances [23], the evidence in our studies suggests that boredom typically impairs attention, motivation, behavioral strategies, and performance in achievement settings.

Teachers have the opportunity to arrange educational environments in order to facilitate students to gain experiences with and learn different types of learning skills.

We concluded that teaching practices were the same combination of teacher regulation practices, and that teachers differed in the degree to which they showed this combination in their educational practice. It is possible that students' perceptions were congruent with the observed classroom pedagogical practices and were therefore in this study a valid indication of teachers' practices.

The result of the present research suggests a more integrated view of the teaching practice than in the research cited: teachers do not teach in one way or another but seem to combine these different approaches. Teachers in the present study are characterized by the combination of different levels of regulation.

Flipped classroom offered teachers two opportunities: a collaboration in which colleagues can meet to explore new technologies and develop teaching strategies; an experimental teaching space where technologies and teaching ideas can be actively tried out with students.

To make flipped lessons successful, it was important to define the quality of the online learning materials and the strong motivations to self-learn of the students. We report the following guidelines and best practices used to remediate attention problems and to improve self-regulation with the flipped classroom: select concepts more easy for the flipped lessons; design the worksheet or assessment alongside with the online materials so as to ensure the students read them readily; enforce the each student to submit one question pertaining to the topic so as to ensure the students read before coming to class; engage students with group activity when meeting face-to-face in class as they learn a lot more effectively with each another.

Observations of instruction inform researchers about real-time teaching practices and about the intervening classroom variables that affect changes in student outcomes. Findings from observations can be used to evaluate and improve the quality of instruction that students receive. Observational data also have the potential to advance the science of learning and build a closer link between research and classroom practice.

From a research perspective, further validation of both instruments, used for measuring teaching and learning among school-wide groups and individual teachers, is important.

\section{ACKNOWLEDGMENT}

We would like to thank all of the student and teachers who participated in this study. We would also like to thank the student teachers who assisted in the data collection, ad our observers who helped code the data, for their work.

\section{REFERENCES}

[1] R. Pekrun, "Emotions in students' scholastic development," in The Scholarship of Teaching and Learning in Higher Education: An Evidence-Based Perspective, R.P. Perry, J.C. Smart (Eds.), Dordrecht, The Netherlands: Springer, 2007, pp. 553-610.

[2] K. B. Mercer-Lynn, R. J. Bar, and J. D. Eastwood, "Causes of boredom: The person, the situation, or both?" Personality and Individual Differences, vol. 56, pp. 122-126, 2014.

[3] D. J. Shernoff, Optimal Learning Environments to Promote Student Engagement, New York: Springer, 2013.

[4] S. Lam, B. P. H. Wong, H. Yang, and Y. Lui, "Understanding student engagement with a contextual model," in Handbook of Research on Student Engagement, S. L. Christenson, A. L. Reschly, C. Wylie, Eds., New York: Springer, 2012, pp. 403-419.

[5] J. D. Eastwood, C. Cavaliere, S. A. Fahlman, and A. E. Eastwood, "A desire for desires: Boredom and its relation to alexithymia," Personality and Individual Differences, vol. 42, no. 6, pp. 1035-1045, 2007.

[6] E. I. Knudsen, "Fundamental components of attention," Annu. Rev. Neurosci., vol. 30, pp. 57-78, 2007.

[7] D. J. Kavanagh, J. Andrade, and J. May, "Imaginary relish and exquisite torture: the Elaborated Intrusion theory of desire," Psychological Review, vol. 112, pp. 446-467, 2005.

[8] E. Kemps, M. Tiggemann, and M. Grigg, "Food cravings consume limited cognitive resources," Journal of Experimental Psychology: Applied, vol. 14, pp. 247-254, 2008.

[9] J. Vogel-Walcutt, L. Fiorella, T. Carper, and S. Schatz, "The definition, assessment, and mitigation of state boredom within educational setting: A comprehensive review," Educational Psychology Review, vol. 24, no. 1, pp. 89-111, 2012.

[10] R. Damrad-Frye and J. D. Laird, "The experience of boredom: The role of the self-perception of attention," Journal of Personality \& Social Psychology, vol. 57, no. 2, pp. 315-320, 1989.

[11] G. L. Macklem, Boredom in the Classroom. Addressing Student Motivation, Self-regulation, and Engagement in Learning, Springer, 2015.

[12] R. Mora. (2011). School is so boring: High stakes testing and boredom at an urban middle school. Perspectives on Urban Education. 9(1). [Online]. Available: http://www.urbanedjournal.org

[13] J. Jisc, Designing Spaces for Effective Learning: A Guide to 21st Century Learning Space Design, Bristol: HEFCE, 2006.

[14] J. Goode, "The digital identity divide: How technology knowledge impacts college students," New Media and Society, vol. 12, no. 3, pp. 497-512, 2010. 
[15] J. Bergmann and A. Sams, Flip Your Classroom: Talk to Every Student in Every Class Every Day, Washington DC: International Society for Technology in Education, 2012.

[16] H. Greene and C. Crespi, "The value of student created videos in the college classroom - An exploratory study in marketing and accounting," International Journal of Arts \& Sciences, vol. 5, no.1, pp. 273-283, 2012.

[17] M. Holtzblatt and N. Tschakert, "Expanding your accounting class with digital video technology," Journal of Accounting Education, vol. 29 , no. 2, pp. 100-121, 2011.

[18] C. J. Brame. (2013). Flipping the classroom. Vanderbilt University, Center for Teaching. [Online]. Available: http://cft.vanderbilt.edu/guidessub-pages/flipping-the-classroom

[19] S. A. Fahlman, K. B. Mercer-Lynn, D. B. Flora, and J. D Eastwood, "Development and validation of the multidimensional state boredom scale," Assessment, vol. 20, no. 1, pp. 68-85, 2013.

[20] A. L. Marca, I Study to Learn How to...thInk, Città Aperta Edition: Troina, 2004.

[21] A. L. Marca, "The development of a questionnaire on metacognition for students in secondary school," in Proc. EDULEARN14 Conference, July 2014, pp. 676-691.

[22] T. Seidel, K. Stürmer, G. Blomberg, M. Kobarg, and K. Schwindt, "Teacher learning from analysis of videotaped classroom situations: does it make a difference whether teachers observe their own teaching or that of others?" Teaching and Teacher Education: An International Journal of Research and Studies, vol. 27, no. 2, pp. 259-267, 2011.

[23] S. J. Vodanovich, "Psychometric measures of boredom: A review of the literature," The Journal of Psychology, vol. 137, no. 6, pp. 569-595, 2003.

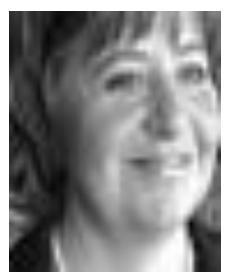

Alessandra La Marca graduated in philosophy at the University of Palermo. She got a Ph.D. in intercultural pedagogy. She is full professor in didactics and pedagogy and teaches educational methodology, educational technologies and experimental pedagogy at the Department of Psychological and Educational Sciences in the University of Palermo. She is a coordinator of $\mathrm{Ph} . \mathrm{D}$. in theory \& practice of education for teacher training of University of Palermo. She is the director of a teacher training book series. Her research focuses on the personalized education, character education, single sex education, metacognitive development, motivation to learning, self-regulated learning and educational innovation in Media education.

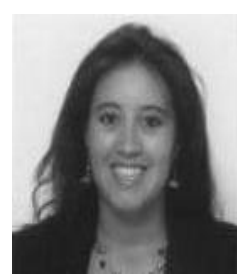

Leonarda Longo graduated in pedagogical sciences from the University of Palermo. She got a Ph.D. in intercultural pedagogy. She is professor in docimology and teachers educational methodology and experimental pedagogy at the Department of Psychological and Educational Sciences in the University of Palermo. She is one member of $\mathrm{Ph} . \mathrm{D}$. commission in theory and practice of education for teacher training of University of Palermo. At the moment, she is involved in the following researches "Flipped classroom methodology", "The didactic use of the multimedia laboratory for the development of metacognitive competences and the self evaluation abilities in university students", Analysis of good practices" (APRED). 